\title{
Numerical Simulation and Experimental Study On Non-Axisymmetric Spinning With a Groove At The Middle of The Tube
}

Zhen Jia ( $\nabla_{\text {jiaz_2006@sina.com ) }}$

Shenyang Aerospace University

\section{Xuan Wang}

Shenyang Aerospace University

Yongping Shen

Shenyang Aerospace University

Yilian Xie

Shenyang Aerospace University

Xue Gong

Shenyang Aerospace University

\section{Baoming Liu}

Shenyang Aerospace University

\section{Research Article}

Keywords: Non-axisymmetric spinning, Middle of the tube, Die-less spinning, Avoidance groove, Roller path

Posted Date: January 3rd, 2022

DOI: https://doi.org/10.21203/rs.3.rs-1182712/v1

License: (c) (i) This work is licensed under a Creative Commons Attribution 4.0 International License. Read Full License 


\title{
Numerical simulation and experimental study on
}

\section{non-axisymmetric spinning with a groove at the middle of}

\section{the tube}

Zhen Jia ${ }^{1,2 *}$, XuanWang ${ }^{2,3}$, Yongping Shen ${ }^{1,2}$, Yilian Xie ${ }^{2,3 *}$, Xue Gong ${ }^{1,2}$, Baoming Liu ${ }^{2}$

1 Faculty of Aerospace Engineering, Shenyang Aerospace University, Shenyang 110136, China

2 Key Lab of Fundamental Science for National Defence of Aeronautical Digital Manufacturing Process, Shenyang Aerospace University, Shenyang 110136, China

3 Faculty of Mechanical and Electrical Engineering, Shenyang Aerospace University, Shenyang 110136, China

*Corresponding authors: jiaz_2006@sina.com, sauylxie@163.com,gongxue_hit@163.com

\begin{abstract}
Spinning is widely used in aerospace and automobile industries, and non-axisymmetric spinning is developing with the increasing demand of irregular shape forming. Based on this, an avoidance groove at the middle of the tube (AGMT) which has potential application value in aircraft structure weight reduction is proposed and formed by using non-axisymmetric die-less spinning. The roller path is analyzed. The relationship between radial displacement of roller and the rotation angle of the tube is deduced. Based on the roller path, 3D finite element model is established. Then, the AGMT spinning experiment is carried out to verify the simulation results. The maximum deviation between the simulation and experimental results is less than $15 \%$. It is indicated that the $3 \mathrm{D}$ finite element model established in this study is reliable and the method for the AGMT forming is feasible. The wall thickness and strain-stress distributions are analyzed. The severe wall thicken and thinning occur in the transition zones, so more attention should be paid to these positions. The depth of the groove has great impact on the forming quality. Deeper groove results in distortion and larger wall thickness difference. The research laid a foundation for the further development and optimization of the AGMT spinning.
\end{abstract}

Key words: Non-axisymmetric spinning, Middle of the tube, Die-less spinning, Avoidance groove, Roller path

\section{Introduction}

As one of the advanced manufacturing technologies, spinning has the characteristics of high flexibility, material and energy saving. And the advantages in short preparation cycle and small batch are self-evident for controlling the carbon emissions. Therefore, spinning is widely used in aerospace, military, and automobile industries such as engine nozzle, aircraft auxiliary fuel tank, rocket booster and so on [1]. Inevitably, the metal spinning process has become more flexible and spinning products also has become divers [2-3]. For increase forming quality, Iacopo M. Russo et al [4] summed up seven principles of toolpath. Therefore, the prospect of the spinning process is bright. According to the blank shape, sheet spinning (which includes conventional spinning and shear spinning) and tube spinning are classified. The tube spinning is used to form cylindrical tubular components with various busbars and can be divided into spinning at the end (SET) and the middle of the tube (SMT) due to the forming position.

For the SET, Takahashi et al [5] performed the neck-in spinning at the end of the tube by double 
rollers and the effects of neck length on the occurrence of cracking were investigated. It is demonstrated that the damage value increases with the neck length. Shreyash Runwal et al [6] developed a method to perform the gas spring tubes on the automobile, which is a spinning process for sealing the end of the tube. A kind of necking-in tube which is used as high-pressure gas vessel was spun by Huang [7] et al at high temperature which shows a better forming result than that at the room temperature, and the forming parameters were also investigated. Otherwise, the end flaring process of the tube can also be realized by spinning. Zhao et al [8] combined the tube spinning and flaring process to form curved generatrix workpiece. The wall thicknesses and mechanical properties in various working conditions were exhibited after spinning. The merits of such process are obvious.

The above investigations focus on the axisymmetric shape. However, the non-axisymmetric spinning can also be applied to form the tube. The non-axisymmetric tube at the end was spun by Xia et al [9-12]. And the tube with this shape can be used as the automobile exhaust pipe with the offset or oblique end. At the same time, the HGPX-WSM CNC spinning machine was developed by Xia et al [13] for manufacturing this product. Steven Wilson et al [14] proposed a method to produce the offset tube at low cost by using a conventional lathe and a simple roller in his work. Although the deviation between the desired and actual geometry existed, it confirmed the possibility of producing the offset tube without any special equipment. An oblique/curved tube spinning process was proposed by Hirohiko Aria et al [15]. They accurately formed the curved shape at the end of the tube. All the tube end spinning in above investigations has diameter reducing.

Besides the SET, the SMT has also been investigated widely. Wu hao et al [16] adopted the finite element simulation to forecast the forming accuracy of the tube spinning with a groove in the middle. Three spinning methods were contrasted in their study to control thickness distribution and suppress the wrinkling defect. Liu et al [17] produced the thick-wall cylindrical part with external grooves using double rollers. Kwiatkowski et al [18] compared different roller trajectories for spinning necking tube without any mandrel and concluded that the value of inclined area as well as the elongation of the part highly depend on the roller path. The researches of Wu hao, Kwiatkowski and Fa mei liu are typical necking spinning processes at the middle of the tube. In order to reduce the production cycle, Zhan et al [19] proposed a mandrel-less neck-in spinning to form the aluminum corrugated tube without any welding seam.

The above studies about the SET include axisymmetric and non-axisymmetric spinning. However, only axisymmetric one was carried out on the SMT. The middle non-axisymmetric tube spinning may be a very interesting topic for the tubular structure with asymmetric features in the middle. For example, when two pipelines cross and meet, if an arc-shaped avoidance groove is produced on one of them (or the both), the pipeline layout space can be greatly saved. This will be of great significance to the structural weight reduction for aircraft. Fig 1 shows the pipelines which are commonly used on the aircraft. And the avoidance groove will be suitable for cable wrapping tubes. In resent researches, the tube avoidance groove using rubber forming was implemented by Yan et al [20]. However, a contour mandrel is needed to inevitably increase the production cost and preparation cycle. The non-axisymmetric tube at the end can be spun, how about on the middle of the tube? 


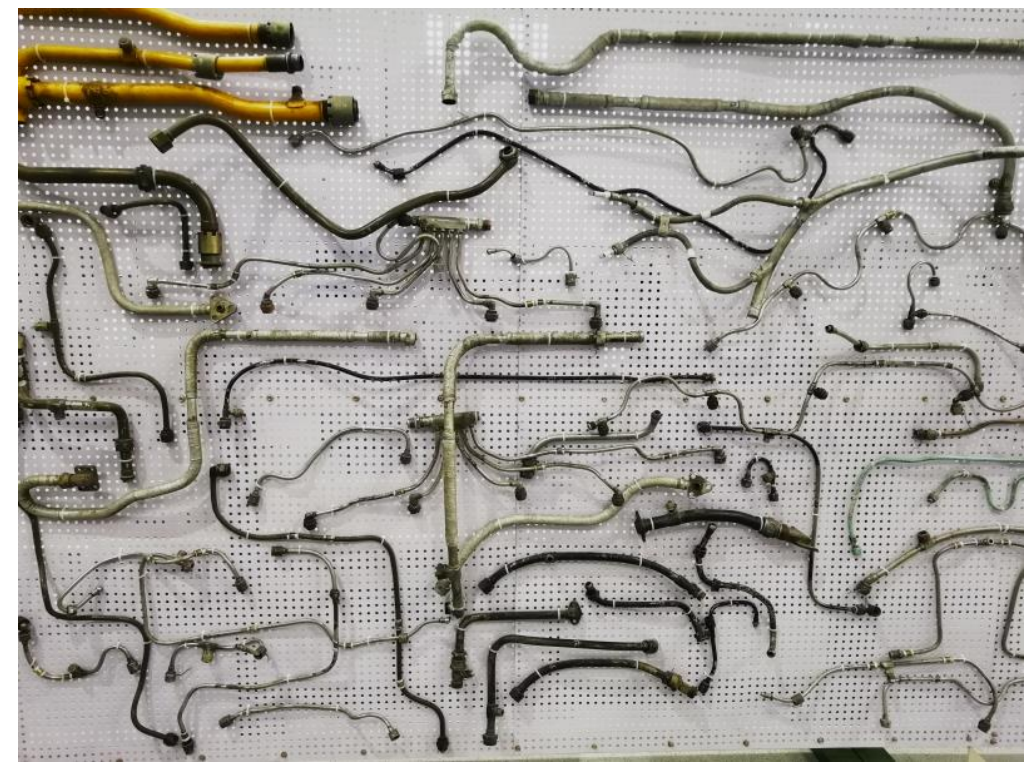

Fig 1 Pipelines on the aircraft

In this study, a non-axisymmetric die-less spinning method is developed for producing an avoidance groove at the middle of the tube (AGMT). Finite element simulation and spinning experiment are adopted to investigate the deforming characteristics and forming quality.

\section{Methodology}

\subsection{Scheme of AGMT spinning}

The characteristic of AGMT showed in Fig2(a). Only one "saddle" shape presents on the tube due to its asymmetry and non-axisymmetric geometric feature. Therefore, traditional spinning method will be not suitable for the AGMT. Fig2(b) shows the design ideal for the unconventional process: the tube blank rotates at a constant speed, and the roller with the corresponding radius (to the saddle arc) extrudes and returns back on the radial direction periodically, however, no axial movement occurs on the roller in the forming process. Finally, the avoidance groove is formed at the middle of the tube. Fig 3 shows the relationship between the radial displacement of the roller and the rotation of the tube blank in every pass. The spindle rotates and drives the tube blank at a constant speed. When the blank rotates an angle, the roller stays at the corresponding position. The time-position relationship between the roller and the spindle rotation is controlled by the numerical control system of the spinning machine.

(a)

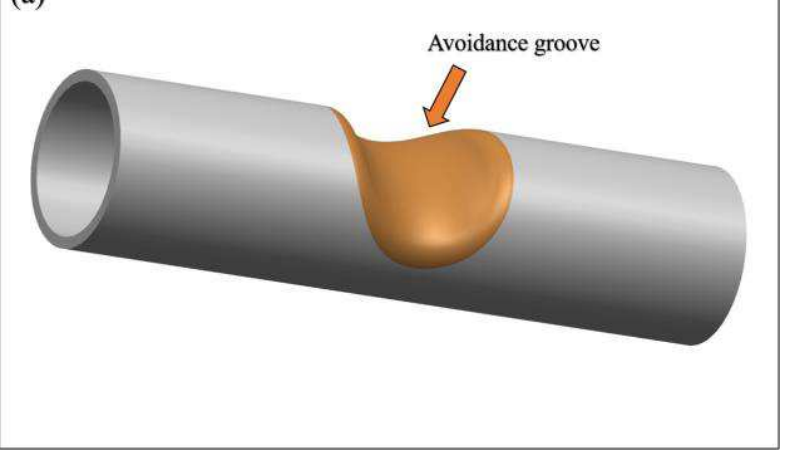




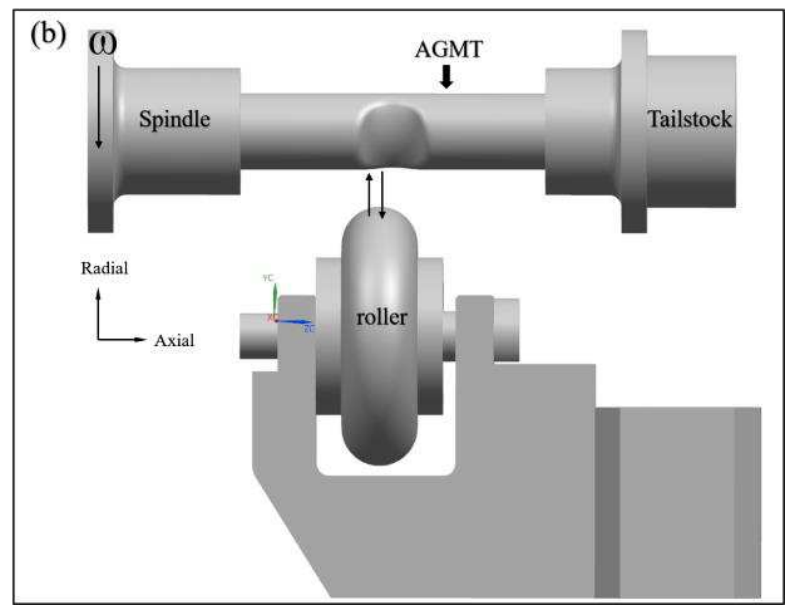

Fig2 (a) Characteristic of AGMT and (b) Ideal of AGMT spinning

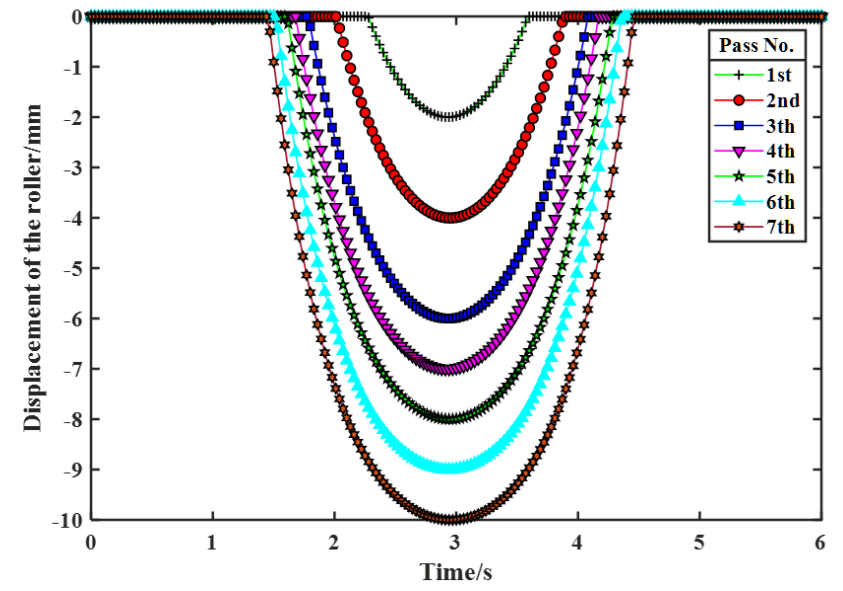

Fig3 Relationship between rotation time of tube blank and displacement of the roller

\subsection{Roller path deduction}

In order to form the "saddle" shape with target depth and radius in the middle of the tube, appropriate roller path is necessary. The forming principle is that the roller reciprocates on the radial direction cooperating with the rotation of tube blank. Hence, the roller path deduction is explained as follow.

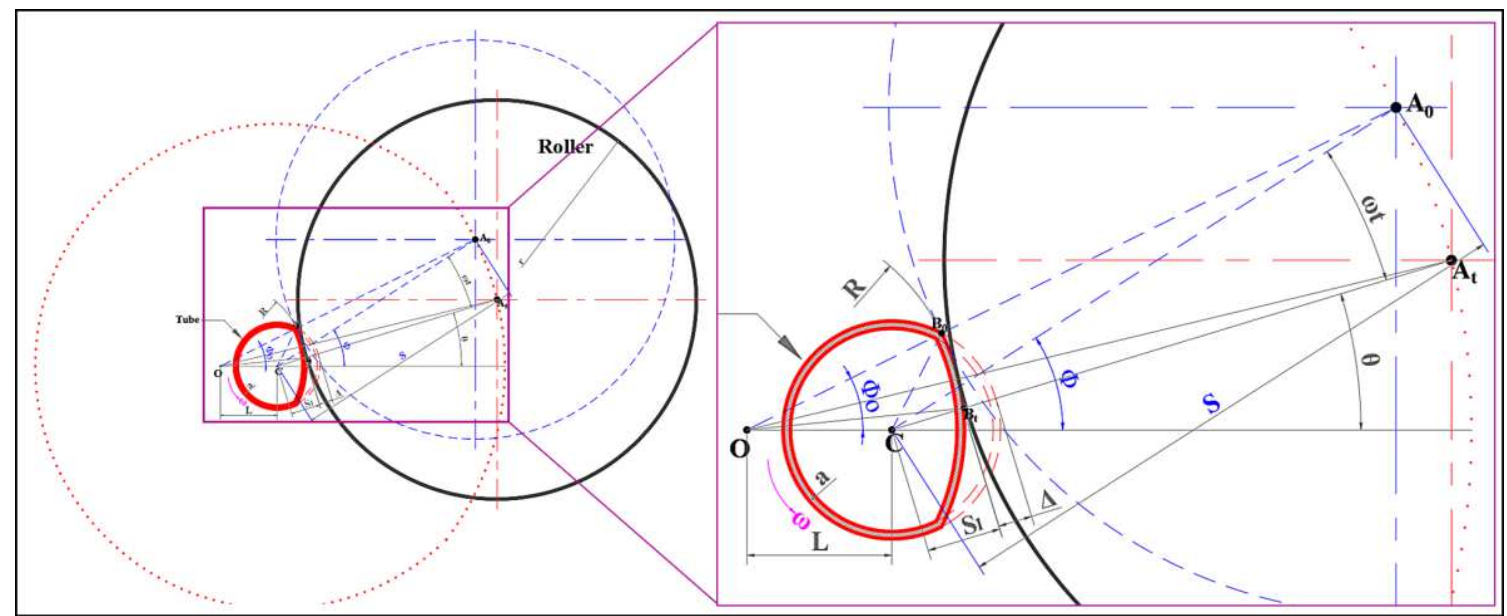

Fig.4 Cross section of tube and roller 
Fig. 4 shows the cross section of the tube and the position the roller path with the rotation angle $\theta$. The radius of roller path under the current pass is $R$; $\mathrm{O}$ is the center of the roller path; $t$ is the time of spinning; when $t$ is 0 , the first deformation point of workpiece is $\mathrm{B}_{0}$ and the center of the roller is $\mathrm{A}_{0}$; At time $t$, the center of roller is $\mathrm{A}_{\mathrm{t}} ; S$ represents the distance between $\mathrm{C}$ and $\mathrm{A}_{0}$; $\mathrm{L}$ represents the distance between $\mathrm{O}$ and $\mathrm{C}$; $\Phi_{0}$ is $\angle \mathrm{B}_{0} \mathrm{OC}$; In the triangle $\mathrm{A}_{0} \mathrm{OC}$, the $\cos \Phi_{0}$ can be represented by eq. (1). In the triangle $\mathrm{B}_{0} \mathrm{OC}$, the $\cos \Phi_{0}$ can be represented by eq. (2)

$$
\begin{array}{r}
\cos \phi_{0}=\frac{L^{2}+(R+r)^{2}-S^{2}}{2 L(R+r)} \\
\cos \phi_{0}=\frac{L^{2}+R^{2}-a^{2}}{2 L R}
\end{array}
$$

From the equitation (1)(2), $\mathrm{S}$ is represented by eq. (3)

$$
S=\sqrt{r^{2}+R r+a^{2}-\frac{r L^{2}}{R}+\frac{r a^{2}}{R}}
$$

Where $\Phi$ is the supplementary angle of $\angle \mathrm{A}_{0} \mathrm{CO}$; According to the eq (1)(2)(3),

$$
\cos \phi=-\frac{r^{2}+R r+a^{2}-\frac{r L^{2}}{R}+\frac{r a^{2}}{R}+L^{2}-(R+r)^{2}}{2 L \sqrt{r^{2}+R r+a^{2}-\frac{r L^{2}}{R}+\frac{r a^{2}}{R}}}
$$

Taking the tube blank as the reference object, $\theta$ is the relative angle of roller during $t$ under current pass. $\theta$ is

$$
\theta=\phi-w t
$$

According to the equation (4) and (5), $\theta$ can be represented by equation (6)

$$
\theta=-\arccos \left(-\frac{r^{2}+R r+a^{2}-\frac{r L^{2}}{R}+\frac{r a^{2}}{R}+L^{2}-(R+r)^{2}}{2 L \sqrt{r^{2}+R r+a^{2}-\frac{r L^{2}}{R}+\frac{r a^{2}}{R}}}\right)-w t
$$

Where $\omega$ is the angular velocity of the tube blank; At time $t, B_{t}$ is a contact point between the roller and tube blank. $S_{1}$ represents the distance between $B_{t}$ and $C, \cos \theta$ is

$$
\cos \theta=-\frac{S_{1}^{2}+L^{2}-R^{2}}{2 S_{1} L}
$$

Combine the equation (6) with equation (7), $S_{l}$ is calculated as follow.

$$
S_{1}=\frac{-2 L \cos \left[w t-\arccos \left(\frac{S^{2}+L^{2}-(R+r)^{2}}{2 L S}\right)\right]+\sqrt{\left\{2 L \cos \left[w t-\arccos \left(\frac{S^{2}+L^{2}-(R+r)^{2}}{2 L S}\right)\right]\right\}^{2}-4\left(L^{2}-R^{2}\right)}}{2}
$$

$$
\Delta=a-S_{1}
$$

Where $\Delta$ is the depth of roller feeding on average pass; In order to express the roller feeding better, take 
the opposite number of $\Delta$ which is exhibited as $\mathrm{f}(\mathrm{t})$. The radial position of roller at any time $\mathrm{f}(\mathrm{t})$ is calculated from equation (8) and (9), and it is exhibited as eq. (10).

$f(t)=\frac{\sqrt{\left\{2 L \cos \left[w t-\arccos \left(\frac{S^{2}+L^{2}-(R+r)^{2}}{2 L S}\right)\right]\right\}^{2}-4\left(L^{2}-R^{2}\right)}}{2}-\frac{2 L \cos \left[w t-\arccos \left(\frac{S^{2}+L^{2}-(R+r)^{2}}{2 L S}\right)\right]}{2}-a$

When $L, R, r, a$ and $\omega$ are defined in the specific situation. The result of equation (10) is shown in the Fig5.

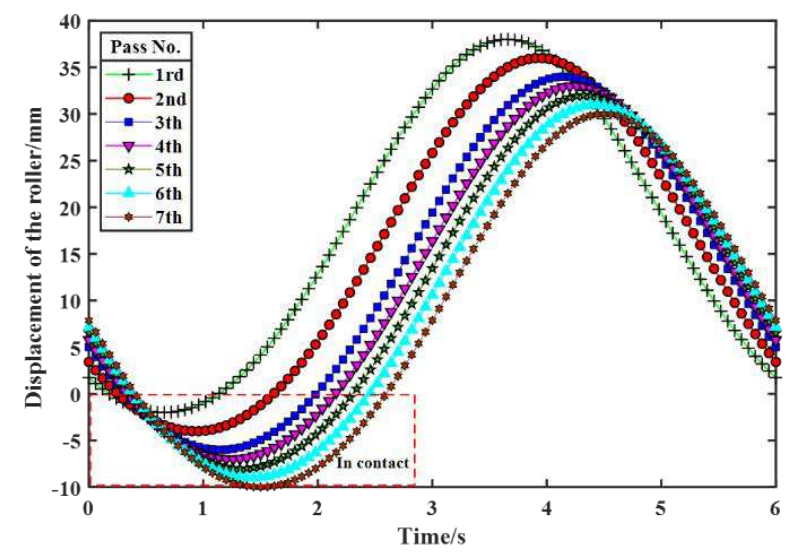

Fig 5 Displacement of the roller per pass

The displacement less than zero indicates that the roller and tube blank are in contact. In other words, there is no contact between the roller and tube blank in other period of time. In order to reduce the motion space of the tool, the displacement more than zero can be replaced by zero. After optimizing, the relationship between the radial displacement of roller and the rotation time of the tube blank per pass is shown in Fig 3.

\section{Finite element analysis and discussion}

\subsection{Establishment of finite element model}

3D Finite element (FE) simulation is widely used in industry. Shorter developing cycle, fewer material waste and lower cost can be achieved by using a reasonable FE simulation. In this study, the FE model of the AGMT spinning is established and the simulation result is compared with the experimental one.

The ABAQUS/ Explicit software is used in this study for the simulation. The 3D geometric model of the roller, spindle, tail cap and tube blank are established. The assembly model of the AGMT spinning is shown in Fig 6.
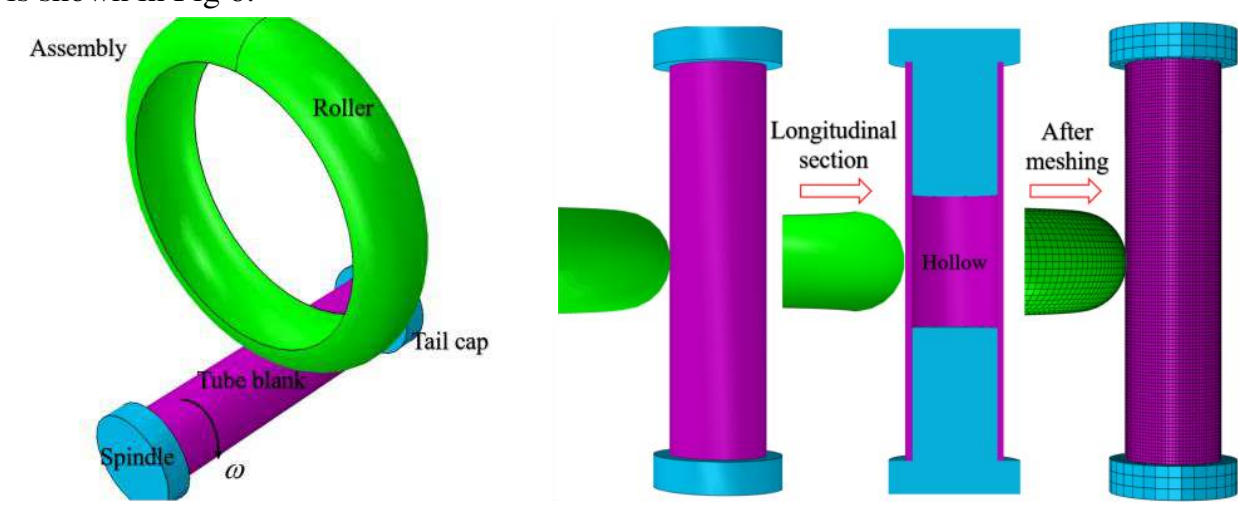

Fig 6 Assembly model of the AGMT spinning

The material of the tube blank is 6063-T6 aluminum alloy. According to the reference [21], the constitutive relationship of the material is expressed as 


$$
\sigma=A+B \varepsilon^{n}
$$

Where $\mathrm{A}, \mathrm{B}$ and $\mathrm{n}$ are the material parameters respectively. $\sigma$ and $\varepsilon$ are the true stress and strain. The stress-strain curve is obtained through the uniaxial tensile test on the MTS testing machine [21]. Fig 7 is the Schematic illustration of stress-strain curve after fitting, the parameters of curve are listed in the table 1 . The mechanical properties of 6063-T6 aluminum ally are listed in the table 2.

Table 1 6063-T6 aluminum alloy stress-strain model parameters

\begin{tabular}{cccccc}
\hline $\mathrm{A} / \mathrm{Mpa}$ & $\mathrm{B} / \mathrm{Mpa}$ & $\mathrm{n}$ & $\mathrm{M}$ & Initial temp/K & $\mathrm{m}$ \\
\hline 170 & 77 & 0.314 & 1.34 & 298 & 0 \\
\hline
\end{tabular}

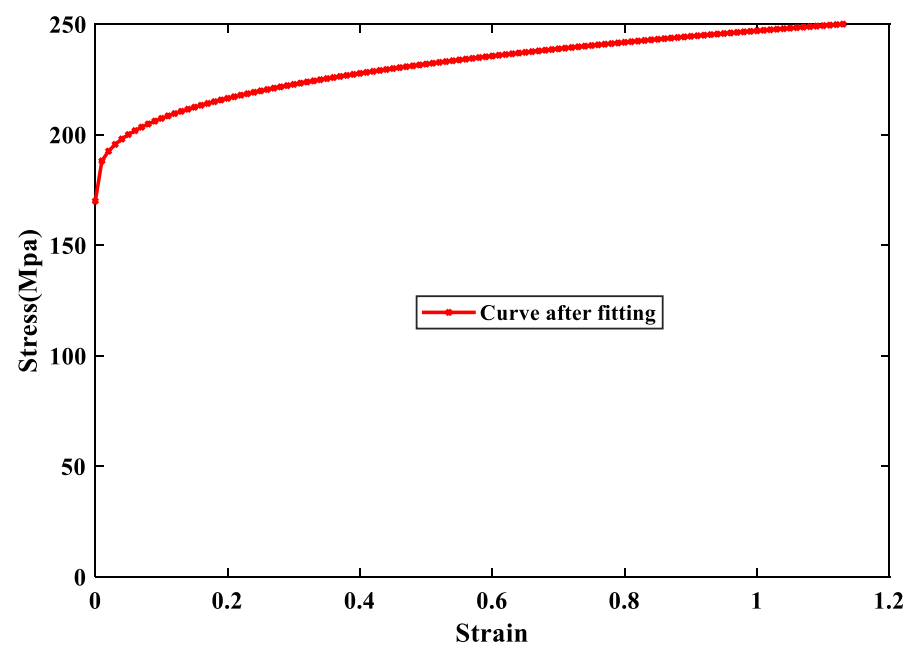

Fig 7 stress-strain curve of 6063-T6 aluminum alloy

Table 2 Mechanical properties of 6063-T6 aluminum alloy

\begin{tabular}{ccc}
\hline Properties & Notation & Steel \\
\hline Elastic modulus & $\mathrm{E}$ & $69 \mathrm{Gpa}$ \\
Poisson's ratio & $\mu$ & 0.33 \\
Yield strength & $\sigma_{\mathrm{s}}$ & $215 \mathrm{Mpa}$ \\
Tensile strength & $\sigma_{\mathrm{b}}$ & $240 \mathrm{Mpa}$ \\
\hline
\end{tabular}

Because the deformation occurs on the roller, spindle and tailstock can be neglected, they are set as rigid body. According to the production experience, the friction coefficients among the inner surface of tube, spindle and tailstock are set to 0.4 without any lubrication. Therefore, the tube blank can be driven by the spindle at the same rotating velocity. In addition, the friction between the outer surface of tube and the roller is blunted by the lubricating oil with the coefficient of 0.1 . The roller path is realized by the boundary condition of the ABAQUS/ Explicit software during AGMT spinning. The tube blank rotates around the axial direction. And the roller has the corresponding radial feed to the blank rotation which turns the roller to rotate around its own axis. This process is shown in Fig 8. The roller movement amplitude is established based on Eq. (10). 


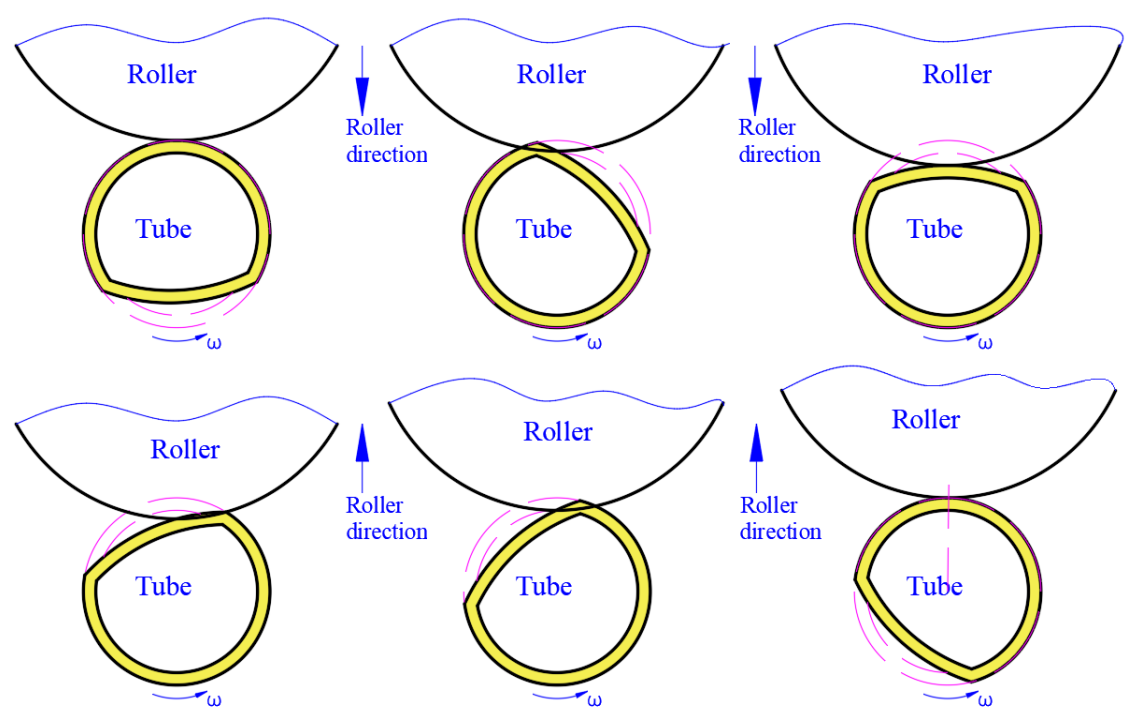

Fig 8 Diagram of the roller path process.

The spindle rotating velocity is $10 \mathrm{rpm}$. The radial reduction per pass $\Delta$ on the tube blank is $2 \mathrm{~mm}$. In the actual spinning working condition, the tube blank is nipped by the spindle and tailstock with a constant force. Therefore, both ends of the tube are applied axial force. The mesh element type of the blank is set as C3D8R (An 8-node linear brick, reduced integration, hourglass control). Theoretically, the more refined and standardized, the more accuracy model will be. The dimension of the element mesh along the thickness and the axial directions is $1 \mathrm{~mm}$ by considering the calculation time, and there are totally 21120 elements and 31944 nodes on the tube.

\subsection{Spinning experiment}

Fig.9 illustrates the PROSPER XY600-5 numerical control spinning machine which is used to carry out the spinning experiment. The assembly of the tube blank, spindle, tailstock and roller in machine is exhibited in Fig. 9 (b). The tube blank is clamped by the spindle and the tailstock which have $40 \mathrm{~mm}$ length axle sticks into the tube on both sides to guarantee the concentricity of the tube, spindle and the tailstock. Moreover, the preformed position on the tube is kept hollow. The dimensions of the roller, tube blank and other tools are equal to the 3D FE model. The diameter of the roller is $140 \mathrm{~mm}$ with the $15 \mathrm{~mm}$ arc radius. The blank dimensions (see Fig.10) - length $(L)$, dimeter $(D)$ and wall thickness $\left(t_{0}\right)$ of $120 \mathrm{~mm}, 30 \mathrm{~mm}$ and $2 \mathrm{~mm}$, respectively. The theoretical depth of the AGMT is set as $6 \mathrm{~mm}$. The rotation of the spindle is $10 \mathrm{rpm}$. The reduction per pass is $2 \mathrm{~mm}$. The blank material and other working conditions are also the same with the simulation. 
(a)

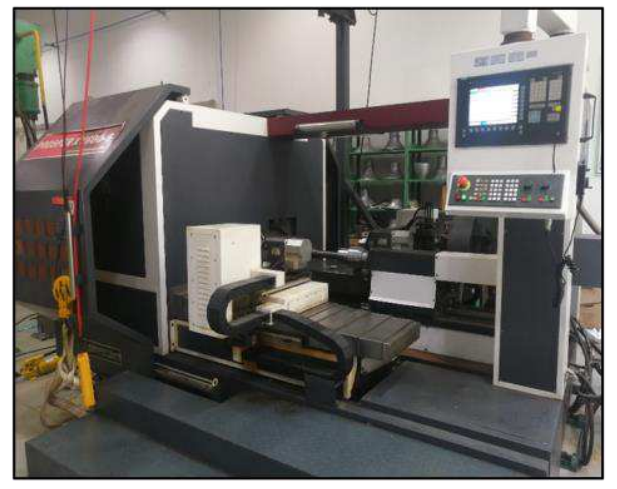

(c)

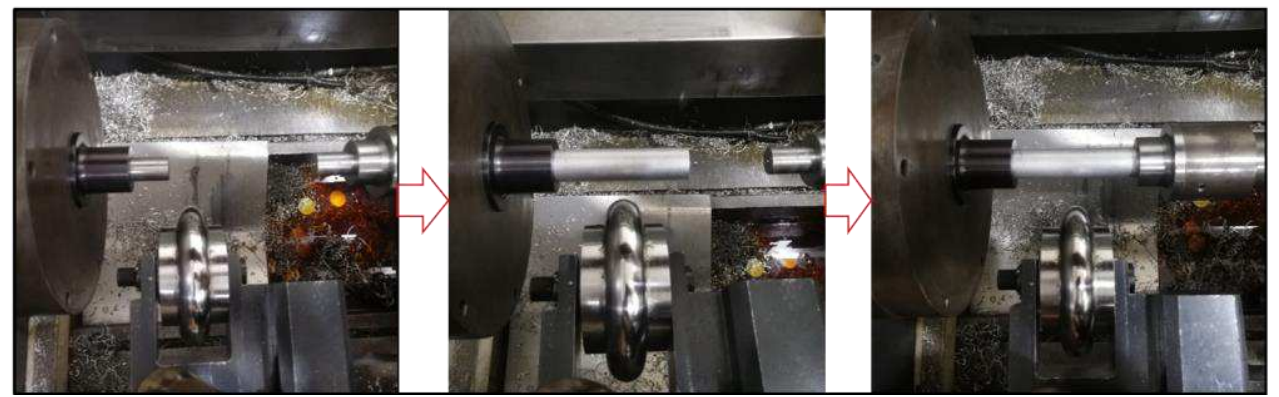

Fig 9 Spinning machine (a) The assembly of tooling for AGMT spinning (b) Clamping process.
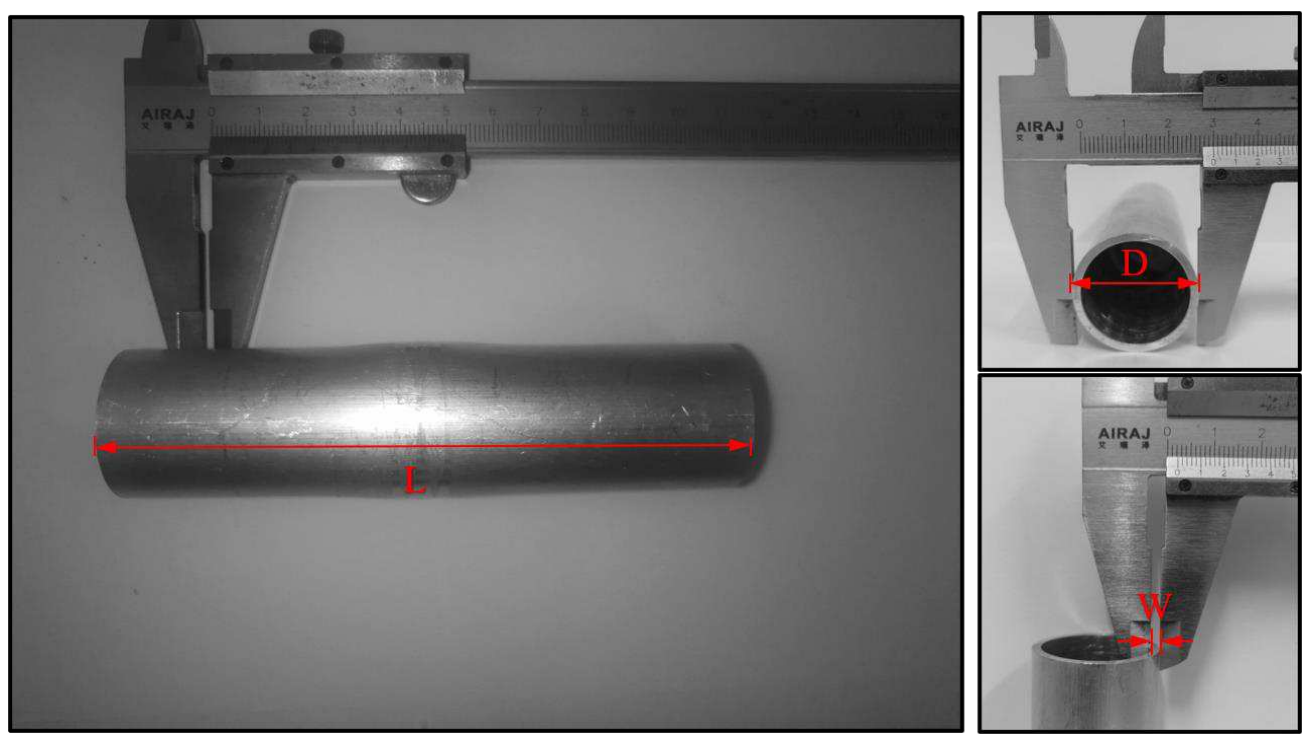

Fig 10 The dimension of the tube

\subsection{Simulation result and verification}

Fig 11 shows the AGMT spinning process, it can be observed that as the roller contacts the tube blank periodically, a local groove with the "saddle" shape is formed in the middle of the tube. Hence the AGMT spinning can be achieved by using the roller path in the 3D FE model. 

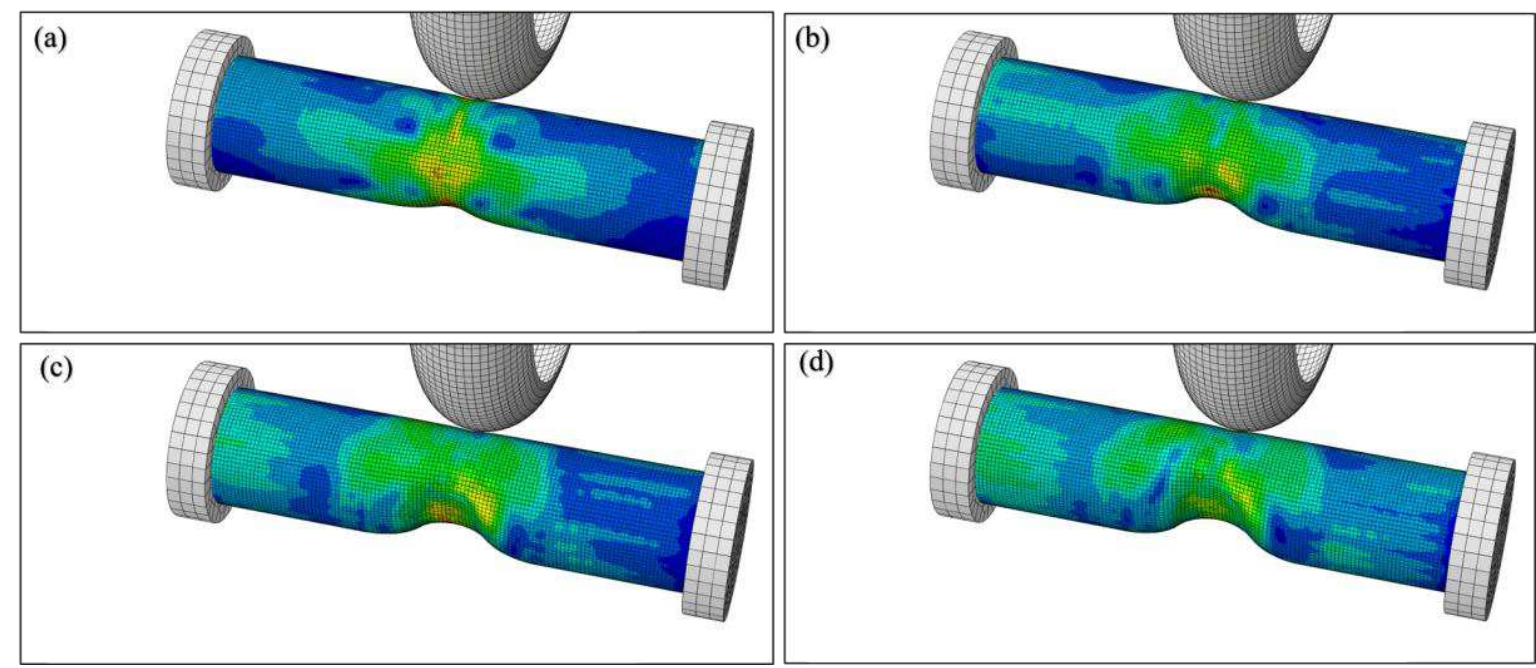

Fig 11 Deformation process of AGMT

Fig 12 shows the experimental result of the AGMT. Obviously, the morphology of the experimental result is in good agreement with the simulated one

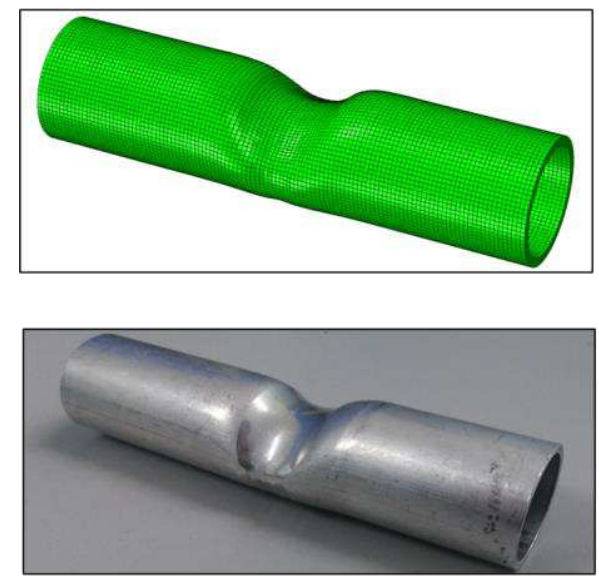

(a)

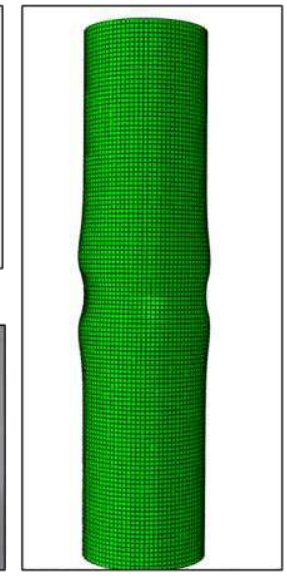

(b)

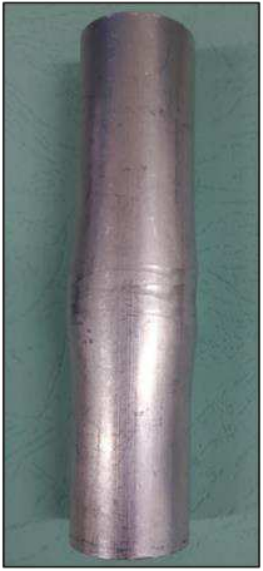

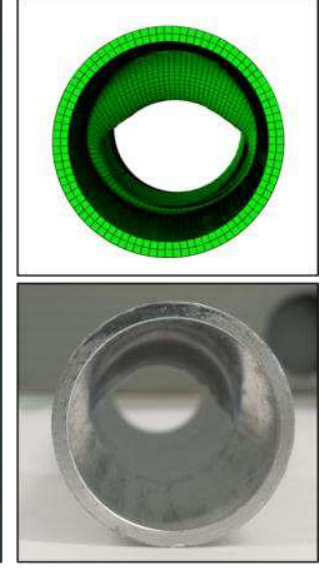

(c)

Fig 12 Experimental and simulation results of AGMT(a) Axonometric (b) Back view (c) End view

Besides the morphology, other dimension parameters of the AGMT such as the sizes and wall thickness are needed to be inspected and contrasted. The dimensional coordinates are set in the middle section of the tube. The Y-Z plane is selected as shown in Fig 13(b), the lowest point of the groove is Q. Point $\mathrm{N}$ is on the outer surface of the tube as well as opposite to the $\mathrm{Q}$. The distance between $\mathrm{N}$ and $\mathrm{Q}$ can be measured directly as $e$. Therefore, depth of the AGMT $h$ shown in Fig. 13(b) is expressed by

$$
h=D-e
$$

By comparing the simulation and experimental results, the $h$ from experiment is $5.88 \mathrm{~mm}$, meanwhile $6.66 \mathrm{~mm}$ in the simulation one. The depth deviation between them is $13.27 \%$. The width of the groove $d$ (Fig. 14) can be calculated by the arc radius ( $\left.r{ }^{\prime}\right)$ of the roller and the depth of the groove. The relationship among $\mathrm{r}$ ', $\mathrm{h}$ and $\mathrm{d}$ is

$$
r^{\prime 2}=\left(\frac{d}{2}\right)^{2}+\left(r^{\prime}-h\right)^{2} .
$$


When the theoretical depth $h$ is $6 \mathrm{~mm}$, the calculated $d$ is $24 \mathrm{~mm}$. However, there is no mandrel at the deforming zone, more material is brought dowm by the roller to increase the width of the AGMT. And the measured widths of the groove $d_{0}$ from experiment and simulation are $29 \mathrm{~mm}$ and $26 \mathrm{~mm}$. .

The wall thickness distributions of the radial (see Fig 13(b)) and longitudinal section (see Fig 13(c)) are investigated respectively. Fig 15 shows the wall thickness distributions on the radial section based on the simulation and experiment. It is found that the trend of two curves is identical. The max relative error is $14.2 \%$. Along the $\mathrm{X}$ direction, the longitudinal section is divided into three parts in the Fig 13(c): the cylindrical zone, concave zone and transitional zone. In the longitudinal section, the measuring points and wall thickness values are shown in Fig 16. A homogeneous wall thickness deviation between the simulation and experiment occurs on the longitudinal section. The maximum error is less than $13 \%$. Therefore, the credibility of the FE model are verified through the morphology and the dimensions of the AGMT.
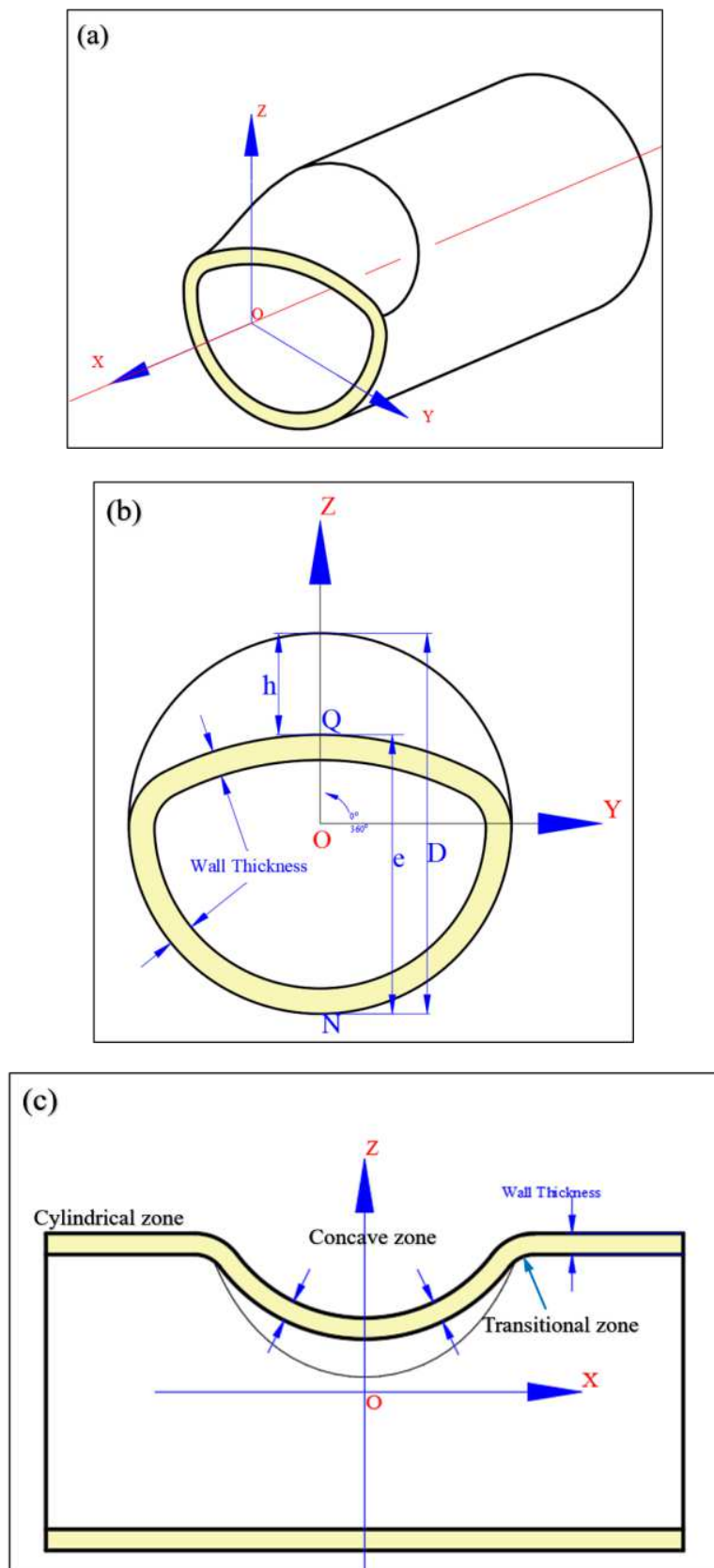

Fig 13 (a) Axonometric drawing of AGMT (b) Radial section (c) Longitudinal section 


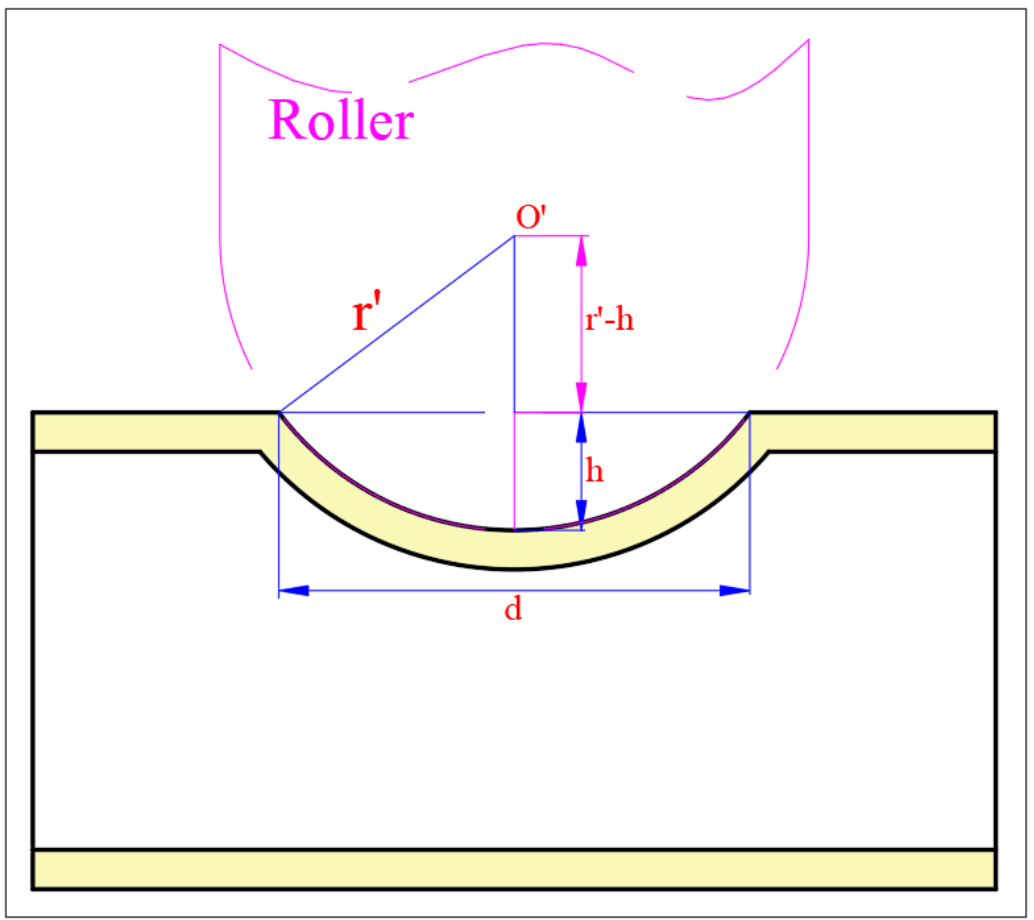

Fig 14 Width calculating model

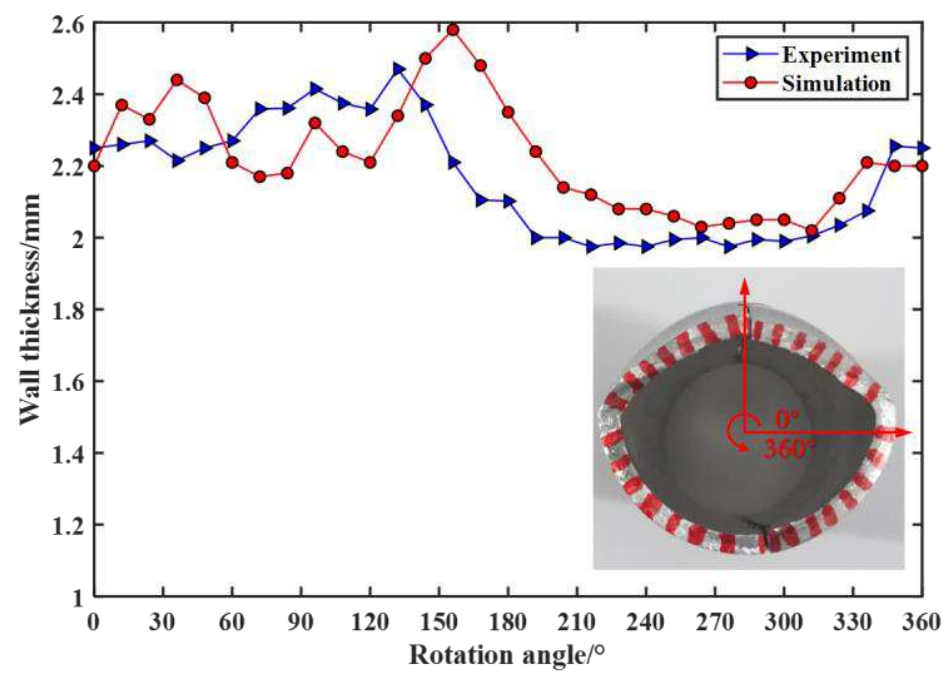

Fig15 Wall thickness distribution on the radial section 


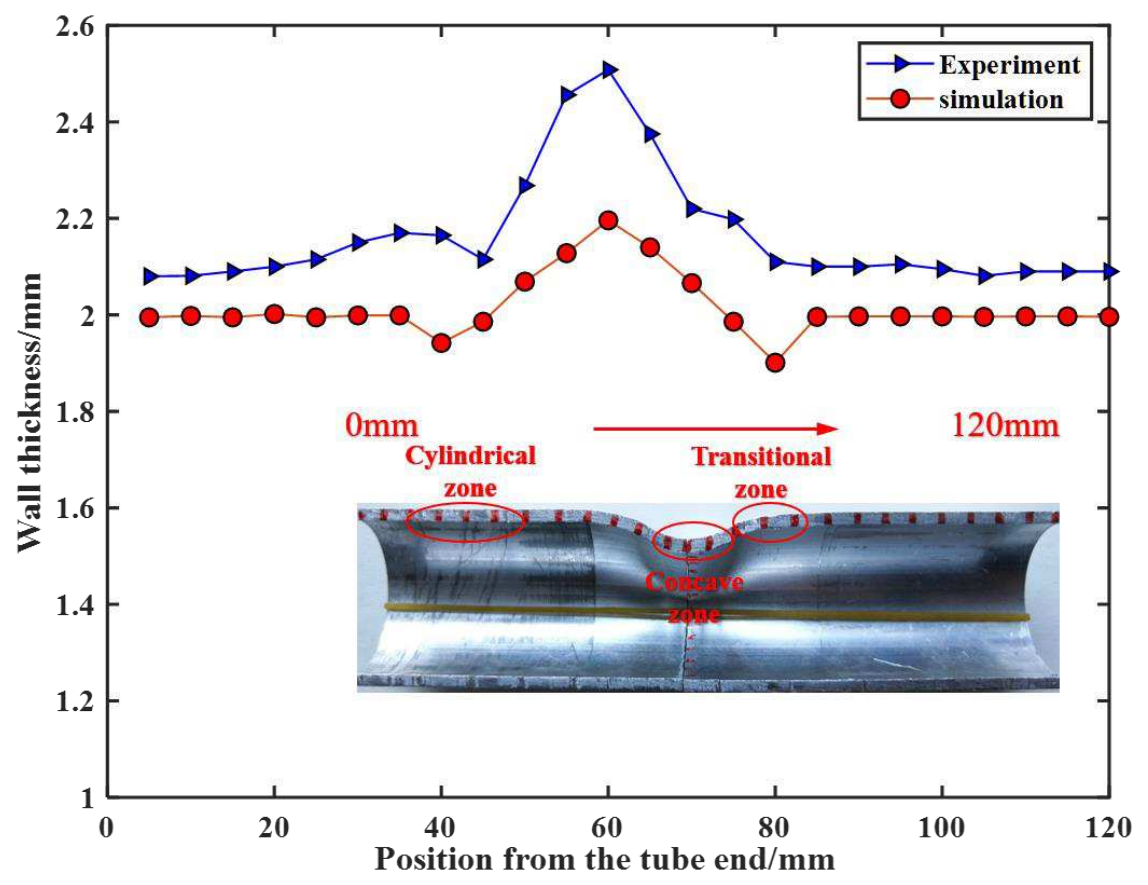

Fig16 Wall thickness along the longitudinal section

\section{Discussion}

\subsection{Wall thickness distribution}

The non-axisymmetric spinning of the AGMT has the uneven wall thickness distributions. At the deforming region along the radial and longitudinal section respectively as shown in Fig 15 and Fig 16. It can be found that from Fig 15, the wall thickness increases on the $0^{\circ}$ to $150^{\circ}$ area and sharply decreases with the rotation angle from $150^{\circ}$ to $180^{\circ}$. And then a stable wall thickness distribution trend appears from $180^{\circ}$ to $360^{\circ}$. Because the main deformation occurs at the area with the $0^{\circ}-180^{\circ}$ rotation angle, the wall thickness in the deforming zone is obviously bigger than that in the non-deforming zone due to the extrusion and accumulation of the metal. From $0^{\circ}-150^{\circ}$ area, the wall thickness increases which indicate that the metal piles up gradually in this area. However, the sharp thinning in $150^{\circ}-180^{\circ}$ area shows that the most of stacked metal doesn't move continuously. The stacked metal is shown as the wrinkle on the groove around $150^{\circ}$ area (see Fig 17). Because of no deformation, the curve in $180^{\circ}-360^{\circ}$ region approximates a straight line. The wall thickness changes obviously at the $0^{\circ}$-direction and $180^{\circ}$-direction positions. The reason is that they are the junctions of the deforming and non-deformation zone. Fig16 shows that there is a uniform deviation between the simulation and experimental wall thickness distribution. The experimental results show that the wall thickness in the axial direction is larger than the original one. The three areas have different wall thickness distribution characteristics. It is demonstrated that the metal flows with the roller pressing. The wall thickness increases from the straight sections on both sides to the bottom of the groove. However, wall thinning occurs on the both transitional zones for whether simulation or experimental result. Therefore, the transitional zone will be focused on due to the thinnest spun wall.

In summary, the wall thickness of the AGMT which is formed by using non-axisymmetric spinning is not homogeneous. The maximum wall thickening takes place on the "saddle center" of the groove whether on axial or longitude section. And obvious thinning appears in the border between two regions with and without deformation. 


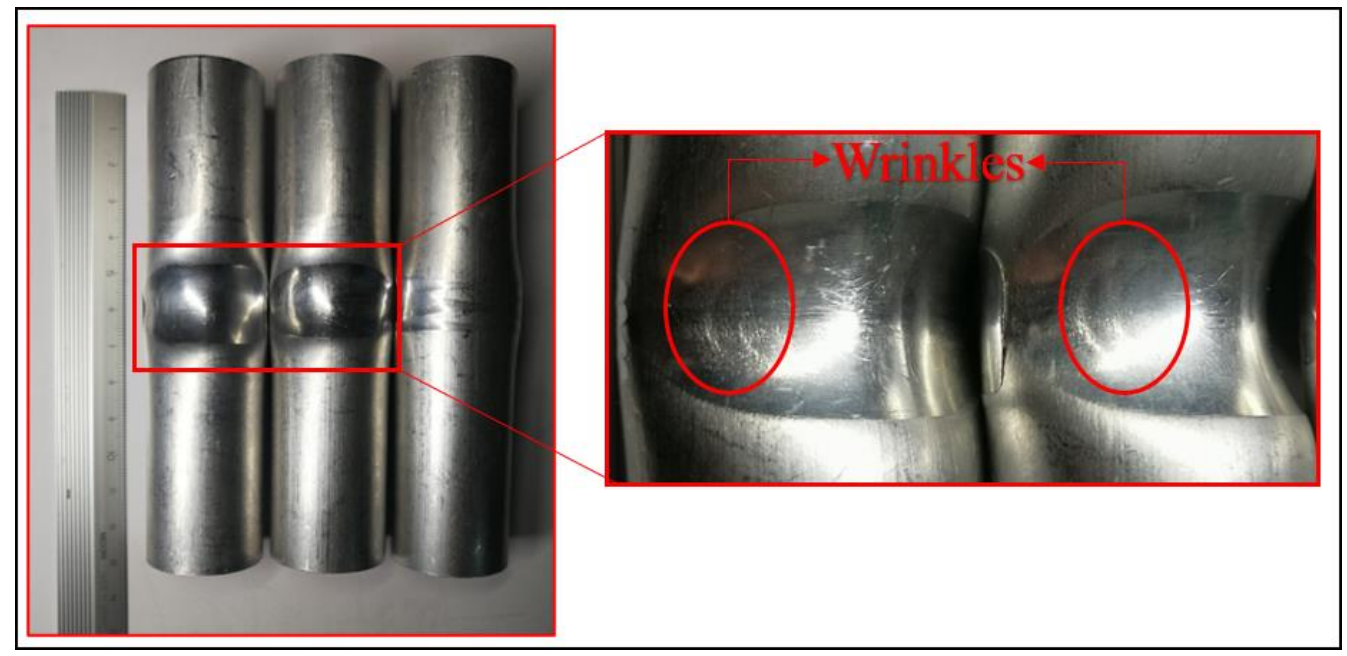

Fig 17 The wrinkles around $150^{\circ}$ area

\subsection{Metal flow field}

Fig18 shows the stress distribution at the spinning time of $0 \mathrm{~s} 1.5 \mathrm{~s} 3 \mathrm{~s} 4.5 \mathrm{~s}$ and $6 \mathrm{~s}$ in the second pass. The total pressing depth of the spinning pass is $4 \mathrm{~mm}$ during $6 \mathrm{~s}$. It can be found that the stress generally symmetrically distributes around the groove along the axial direction. At the beginning of this pass, local stress focus on at the $90^{\circ}$ area where is the "saddle center". The area with high stress expands gradually as the spinning process. The maximum stress emerges at the spinning time of $3 \mathrm{~s}$, meanwhile the rolling reduction reaches the maximum value. The equivalent stress is gradually stable after the roller leaving from the groove. The maximum stress locates at the $90^{\circ}$ position through the whole pass, and the large residual stress is easy to cause spring back to affect the forming accuracy.
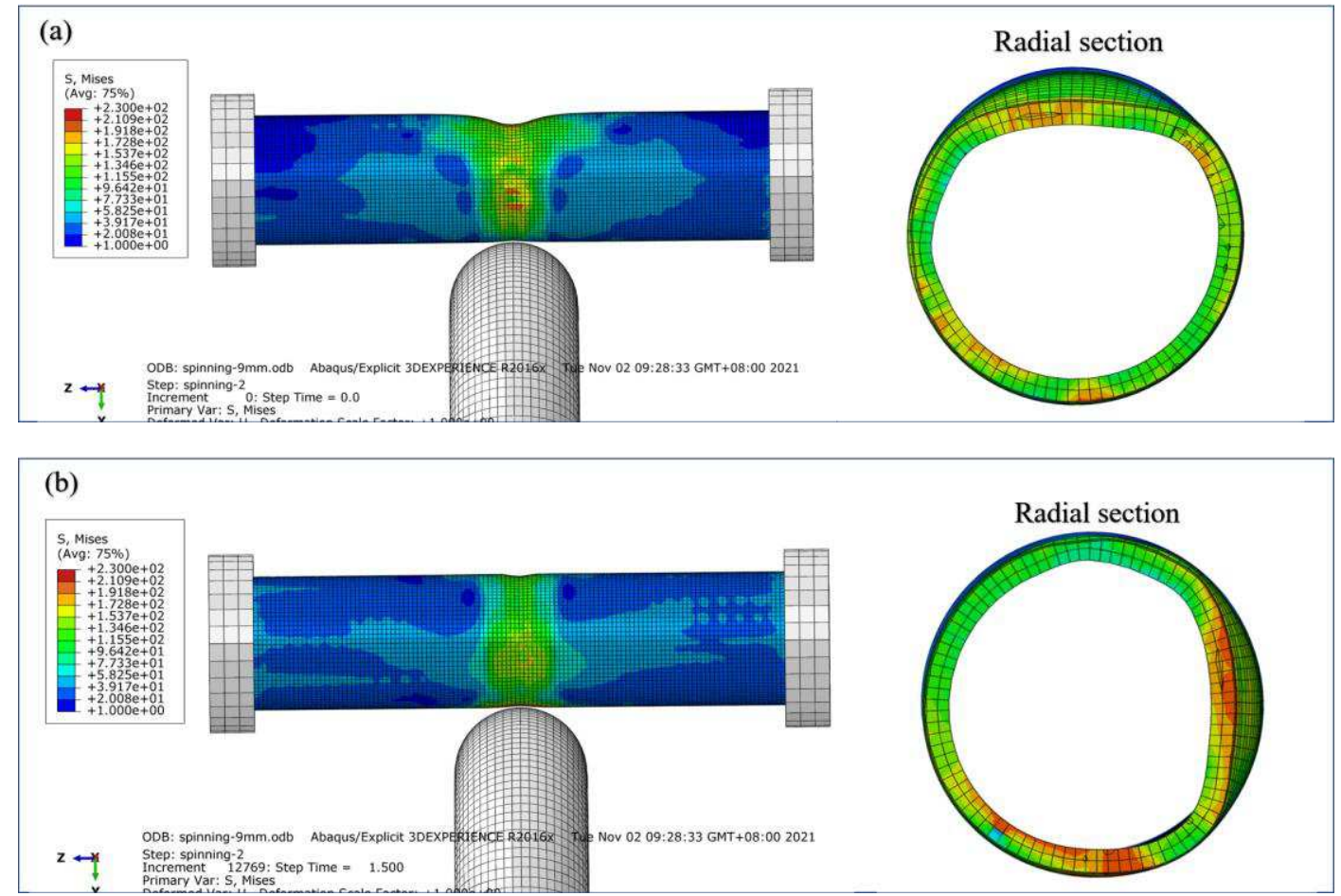

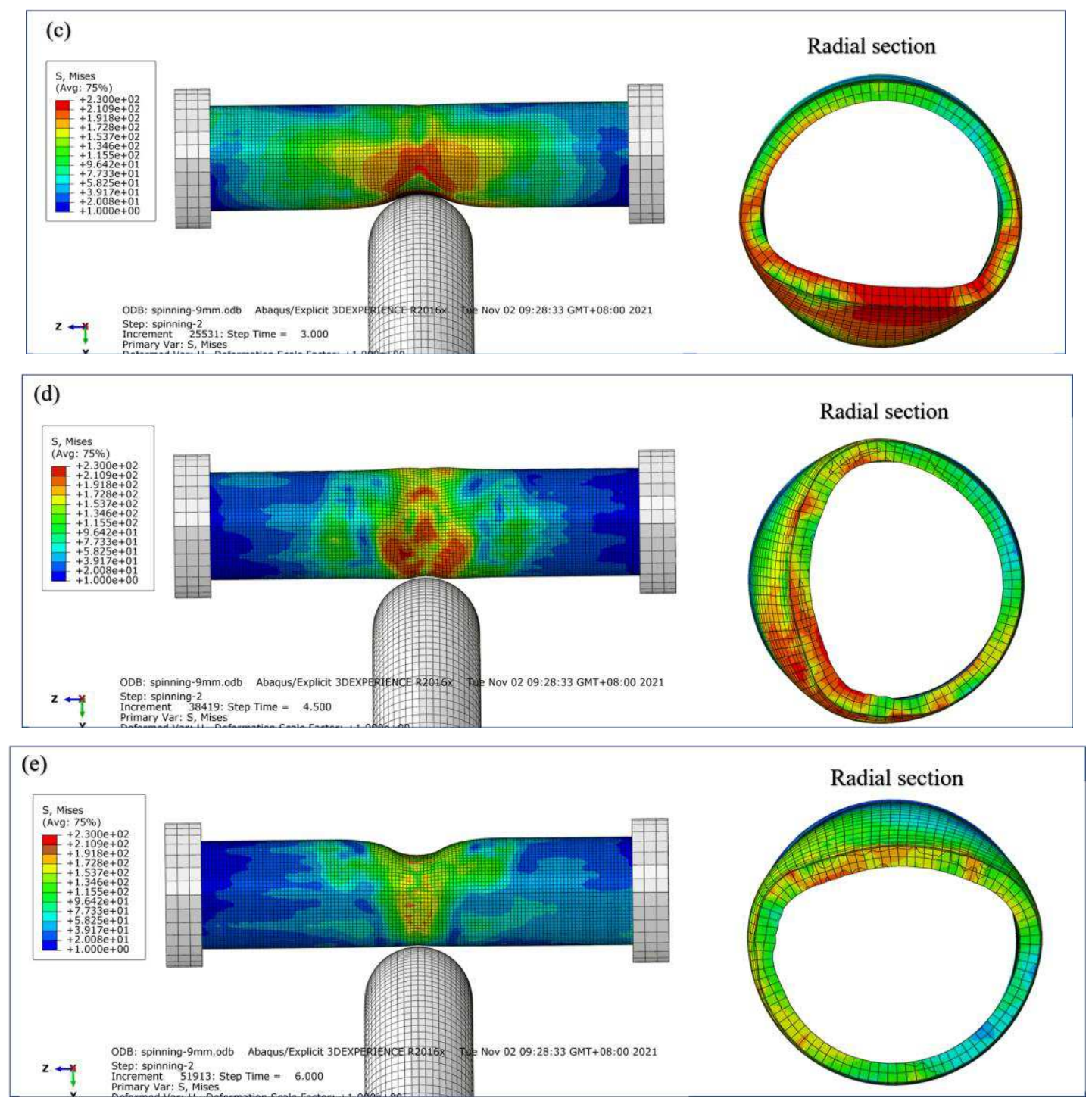

Fig 18 Equivalent stress in the second pass at (a) $0 \mathrm{~s}$, (b) $1.5 \mathrm{~s}$, (c) $3 \mathrm{~s}$, (d) $4.5 \mathrm{~s}$, (e) $6 \mathrm{~s}$.

Fig 19 shows the distribution of equivalent strain in the second pass. It shows that the maximum strain also occurs on the "saddle center" of the AGMT with the largest deformation. It is known that from the study of wall thickness distribution, the larger strain originates from the increase of wall thickness. That means the metal gradually accumulates on the groove with the "saddle" shape forming, and the sides of the "saddle" shape are leaded to exceed the cross-section profile of the tube blank. When the roller spins over the excess metals during the pass time of $3 \mathrm{~s}-6 \mathrm{~s}$, the wrinkling defect is formed in the corresponding area. On the other hand, the mechanism can be revealed as that, lager tangential stress than that in other areas is formed on the junctions between the deforming and non-deformation zones due to the "saddle" shape, therefore the metal has to flow along the tangential direction, resulting in a mount material accumulation on the subsequent roller path. When the metal is rolled over, the wrinkles appear. 


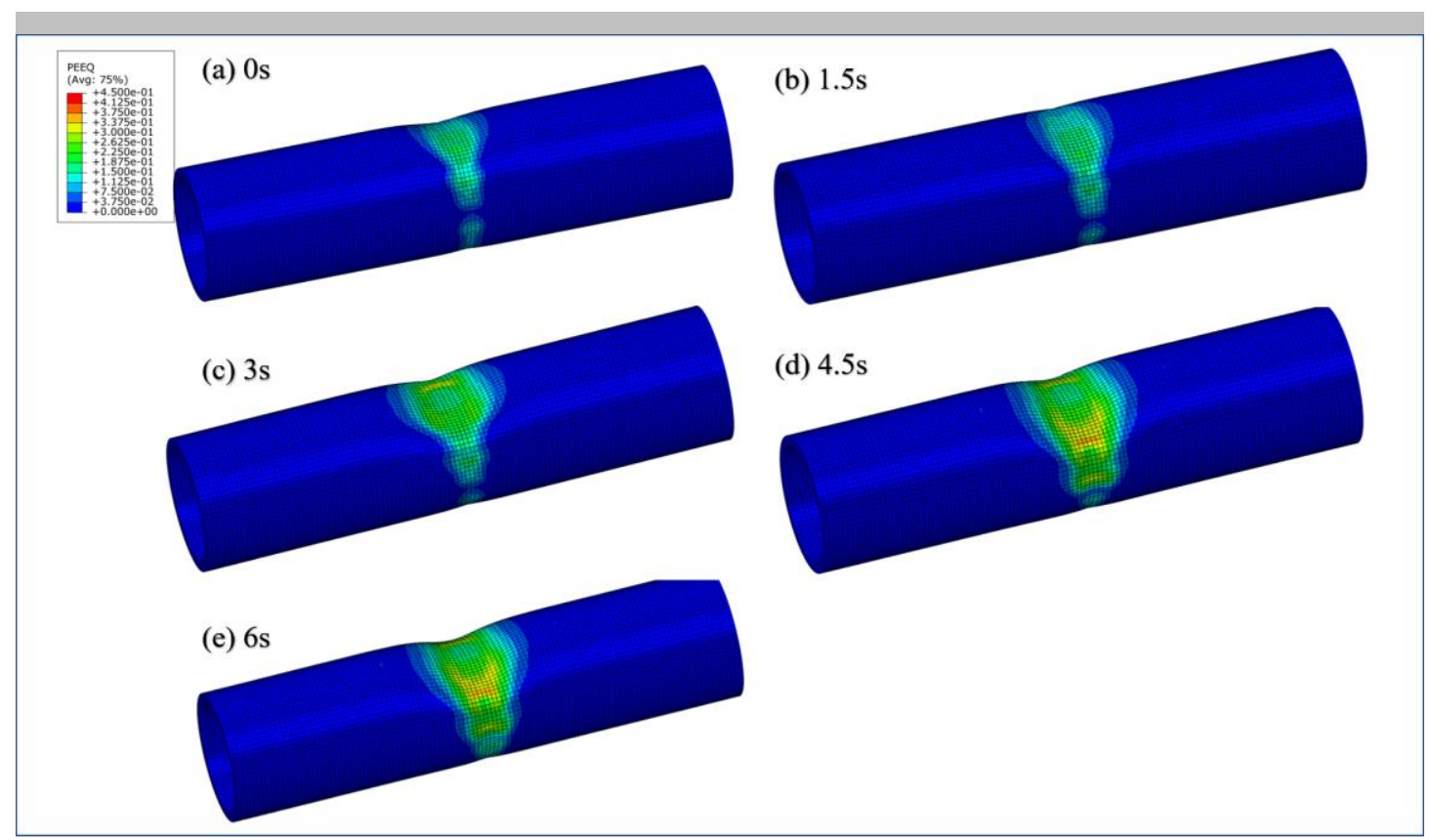

Fig 19 Distribution of strain in the second pass at (a) $0 \mathrm{~s}$, (b) $1.5 \mathrm{~s}$, (c) $3 \mathrm{~s}$, (d) $4.5 \mathrm{~s}$, (e) $6 \mathrm{~s}$.

\subsection{Effects of spinning depth}

The spinning depth $h$ not only directly determines the shape dimensions of the groove, but also affects the wall thickness and stress-strain distributions, and then affects the mechanical properties of spun part. Therefore, the working conditions with the $h$ of $6 \mathrm{~mm}, 7 \mathrm{~mm}, 8 \mathrm{~mm}$ and $9 \mathrm{~mm}$ are simulated. Fig 20 shows the simulation results.

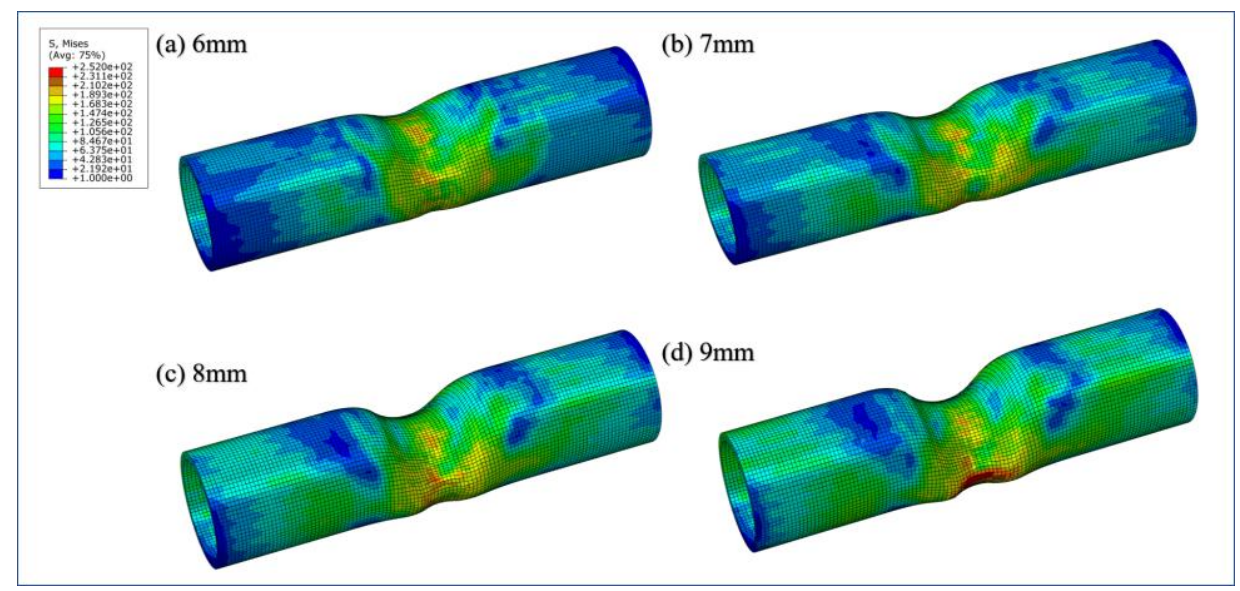

Fig 20 Simulation results with the spinning depth of (a) $6 \mathrm{~mm}$, (b) $7 \mathrm{~mm}$, (c) $8 \mathrm{~mm}$ and (d) $9 \mathrm{~mm}$.

It can be found that, the "slender waist" defect emerges and deteriorates with the spinning depth from $6 \mathrm{~mm}$ depth to $9 \mathrm{~mm}$. And the distributing stress on the AGMT increases and expands. The wall thickness distributions of the four working conditions on longitudinal section are shown in Fig 22. The trends of the curves with the four spinning depths are the same. However, it is obviously that there is larger wall thickness difference in deeper groove. Greater wall thinning occurs in transition zone between the groove and the cylinder with the increase of the spinning depth. In addition, the wall thickening happens at the "saddle center" of the groove, the wall thickness increases with the spinning depth. Fig23 shows the wall thickness distributions of the four working conditions on the radial section. 
The maximum wall thickness fluctuation occurs in the region of $0^{\circ}$ and $180^{\circ}$ for the four working conditions. The wall thickness with $9 \mathrm{~mm}$ spinning depth is obviously bigger than that with $6 \mathrm{~mm}$ one. Therefore, deeper spinning of the AGMT will result in bigger wall thickening and shape distorting, and the parameters optimizing and roller path amending need to be further investigated for it.

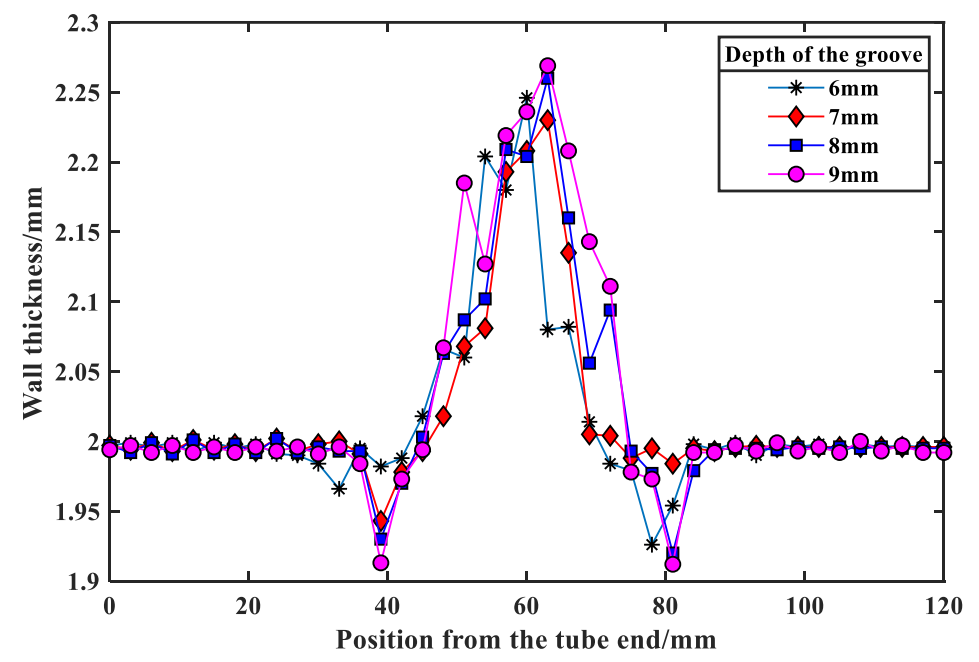

Fig 21 Wall thickness distribution in longitudinal section

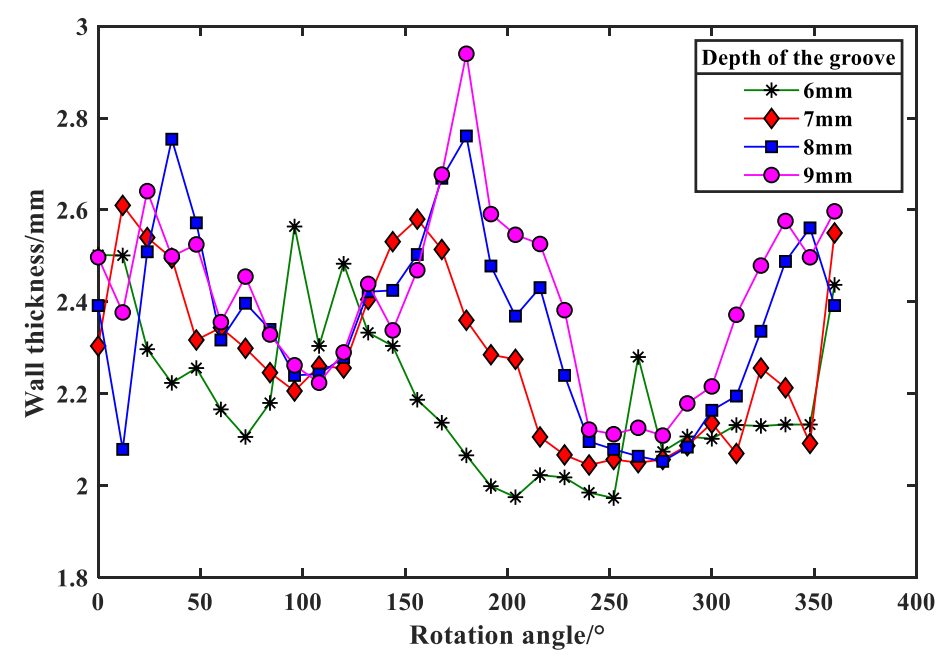

Fig 22 Wall thickness distribution in radial section

\section{Conclusions}

In this study, the non-axisymmetric spinning of AGMT is proposed. The feasibility of the new method is verified by the $3 \mathrm{D}$ finite element modeling and the spinning experiment. Following conclusions are expressed:

(1) The roller path is deduced through the theoretical analysis and imported into the finite element model by being used as the boundary condition. The experiment with completely consistent parameters is carried out to verify the simulation result. And the geometric morphology and dimensions of the simulation and experiment results have good agreements.

(2) The wall thickness distributions along the radial and axical directions are measured and analyzed. The non-axisymmetric spinning of the AGMT has the inhomogeneous wall thickness 
distributions due to its "saddle" shape. The maximum stress and strain occur on the "saddle center". The wrinkling defect is formed by the being crushed metal which is accumulated on the side of the "saddle".

(3) The spinning depth on the groove has great influence on the forming quality of AGMT. The wall thickness and shape distortion increase with the spinning depth due to the more metal flow.

\section{Declarations}

a. Funding

This work was supported by the Aviation Science Foundation, China (No. 2018ZE54028), Open Foundation of Key Lab of Fundamental Science for National Defense of Aeronautical Digital Manufacturing Process, China (No. SHSYS202005). Liaoning Provincial Department of Education Fund, China (No. JYT2020005). The authors wish to express their gratitude.

b. Conflicts of interest/Competing interests

The authors declare no competing interests

c. Availability of data and material

Not applicable

d. Code availability

Not applicable

e. Ethics approval

Not applicable

f. Consent to participate (include appropriate statements)

The authors declare that they are all co authors of this manuscript.

g. Consent for publication

The authors declare that they all agree to publish this manuscript.

h. Authors' contributions

Zhen Jia proposed the method, carried out the experiments and revised the manuscript. Xuan Wang designed the roller path, established the finite element model and wrote the manuscript. Yongping Shen and Yilian Xie improved the finite element model and participated the tooling design and processing. Xue Gong and Baoming Liu put forward valuable suggestions for the English writing and provided project support. All the authors participated the result discussion of the manuscript.

\section{References}

[1] Long JC, Xia QX, Xiao GF, Cheng XQ. Application status and Prospect of spinning technology in national defense industry. Proceedings of the first weapons Engineering Conference 2017; 1155-1159 (In Chinese).

[2] Music O, Allwood JM, Kawai K. A review of the mechanics of metal spinning. Journal of Materials Processing Tech 2010; 210(1):3-23.

[3] Wong CC, Dean TA, Lin J. A review of spinning, shear forming and flow forming processes. International Journal of Machine Tools \& Manufacture 2003; 43(14):1419-1435.

[4] Russo IM, Cleaver CJ, Allwood JM. Seven principles of toolpath design in conventional metal spinning. Journal of Materials Processing Technology 2021; 294(4):117131.

[5] Takahashi Y, Kihara S, Nagamachi T, Higaki K. Effects of neck length on occurrence of cracking in tube spinning. Procedia Manufacturing 2018; 15:1200-1206.

[6] Runwal N, Kathiresan G, Karthikeyan P, Jeyanthi S, Bade S. Numerical and Experimental Analysis 
of Spinning Process for Gas Spring Tube. Materials Today: Proceedings 5 2018; 18176-18186.

[7] Huang CC, Hung JC, Hung C, Lin CR. Finite element analysis on neck-spinning process of tube at elevated temperature. The International Journal of Advanced Manufacturing Technology 2011;56(9-12).

[8] Zhao XK, Xu WC, Chen Y, Ma H, Shan DB. Fabrication of curved generatrix workpiece of TA15 titanium alloy by variable thickness tube spinning and flaring process. International Journal of Advanced Manufacturing Technology 2017;88 (1980-1992).

[9] Xia QX, Shang Y, Zhang SB, Ruan F. Numerical Simulation and Experimental Investigation on the Multi-pass Neck-spinning of Non-axisymmetric Oblique Tube. Chinese Journal of Mechanical Engineering 2008; 44(8).

[10] Xia QX, Cheng XQ, Hu Y, Ruan F. Finite element simulation and experimental investigation on the forming forces of 3D non-axisymmetrical tubes spinning. International Journal of Mechanical Sciences 2012;48(7):726-735.

[11] Xia QX, Cheng XQ, Hui L. Finite element analysis and experimental investigation on deformation mechanism of non-axisymmetric tube spinning. International Journal of Advanced Manufacturing Technology 2012; 59(1-4):263-272.

[12] Xia QX, Liang BX, Zhang SJ, Cheng XQ, Ruan F. Finite Element Simulation on the Spin-forming of the 3D Non-axisymmetric Thin-Walled Tubes. Journal of Materials Science \& Technology 2006;22(02): 261-286.

[13] Hu X, Xia QX, Cheng XQ. Structural design of HGPX-WSM horizontal type CNC spinning machine with double rollers. Forging \& Stamping Technology 2014; 39(08):59-64.

[14] Wilson S, Long H, Garter G. Non-axisymmetric tube spinning by offset rotation. Procedia Manufacturing 2018, 15:1247-1254.

[15] Arai H, Gondo S. Oblique/Curved Tube Necking Formed by Synchronous Multipass Spinning. Metals - Open Access Metallurgy Journal 2020; 10(6):733.

[16] Wu H, Jia Z, Han ZR. Research on finite element simulation of hollow spinning for tubular part with concave arc generatrix. Forming \& stamping technology 2016 (2):84-90.

[17] Liu FM, Jin JS, Rao W, Wang Y. Study of Dieless Radial Spinning for Thick-Walled Cylindrical Parts With External Grooves. The International Journal of Advanced Manufacturing Technology 2021(05).

[18] Kwiatkowski L, Melsheimer O. Experimental investigation of tool path strategies for incremental necking-in. International Journal of Material Forming 2010; 3(1 Supplement):967-970.

[19] Zhan M, Shi F, Deng Q. Forming mechanism and rules of mandreless neck-spinning on corrugated pipes. Journal of Plasticity Engineering 2014; (2):108-115

[20] Yan B. Development if finite element modeling module and research on process parameters of rubber forming. The Master's Degree, ShenYang Aerospace University, Shen Yang CHINA 2020.

[21] Fu AJ. Hyper-plasticity Mechanism of Electromagnetic Expanding Forming for Aluminum Alloy Tube. The Master's Degree, Ningbo University, Ning Bo CHINA 2017. 